\title{
Clinical characteristics of men with non-mosaic Klinefelter syndrome in northeastern China: implications for genetic counseling
}

\author{
M. Zhang, H.-T. Fan, H.-S. Zheng, Q.-S. Zhang, S.-Q. Feng and R.-W. Li \\ Andrology Laboratory, Department of Urology, \\ The Second Hospital of Jilin University, Changchun, Jilin Province, China \\ Corresponding author: M. Zhang \\ E-mail: zhangming1982jdey@126.com \\ Genet. Mol. Res. 14 (3): 10897-10904 (2015) \\ Received March 26, 2015 \\ Accepted June 13, 2015 \\ Published September 9, 2015 \\ DOI http://dx.doi.org/10.4238/2015.September.9.27
}

\begin{abstract}
Klinefelter syndrome (KS) is the most common genetic cause of male infertility. Widespread development in assisted reproductive technology has provided non-mosaic KS patients with the opportunity of having biological children. Testosterone replacement therapy and micro-dissection testicular sperm extraction are effective sperm retrieval techniques for KS patients. Despite the success of sperm retrieval and intracytoplasmic sperm injection (ICSI), some areas of early aggressive hormonal spermatogenesis and appropriate management of KS remain controversial. Androgenotherapy, a common treatment for KS, carries a risk of decreasing focal spermatogenesis by lowering the gonadotropin content. Inadequately treated hypogonadism increases psychosocial morbidity in KS patients. Preventive care must be provided from the time of diagnosis, preferentially through a multidisciplinary approach. This indicates the need for improved genetic counseling of KS patients. The aim of this study was to report the prevalence of non-mosaic KS in a Chinese infertile male population. The rate of early diagnosis was lower in KS patients; most of these were diagnosed after rising concerns of reproductive capacity. The mean age of patients with sperm or germ cells
\end{abstract}


was significantly lower, while the semen volume of these patients was significantly higher. However, the semen volume was negatively correlated with the age and ratio of luteinizing hormone/testosterone content in KS patients. Therefore, genetic counseling of KS patients should focus on early diagnosis and timely treatment, in addition to improving the quality of life of all KS patients. The use of testosterone replacement therapy and/ or micro-dissection testicular sperm extraction should be preferentially considered for fertility preservation.

Key words: Klinefelter syndrome; Genetic counseling; Quality of life; Multidisciplinary approach

\section{INTRODUCTION}

Klinefelter syndrome (KS) is the most common genetic cause of male infertility and primary testicular failure. The prevalence of KS, ranging from 1/500 to 1/1000 in newborn male infants, has increased by $3-4 \%$ among infertile males and $10-12 \%$ in azoospermic patients (Forti et al., 2010). Most men are diagnosed late, when fertility problems arise, while some even remain undiagnosed (Bar et al., 2014). Thus far, only one-quarter of all persons with KS have been diagnosed during their lifetimes (Nieschlag, 2013).

In the past, men with this syndrome (especially the non-mosaic type), were considered to have no chance of becoming biological fathers (Bar et al., 2014). However, currently, with the widespread application of assisted reproductive technology, non-mosaic KS patients have been provided with the opportunity of having biological children. The technological development in testicular sperm extraction-intracytoplasmic sperm injection (TESE-ICSI) has assisted over $50 \%$ of the men (with this syndrome) suffering this problem (Bar et al., 2014).

In some cases, viable sperms were obtained from individual testicular tubules by biopsy, allowing for these patients to become fathers (Nieschlag, 2013). In very few cases, men with nonmosaic Klinefelter syndrome ejaculate spermatozoa (Crüger et al., 2001; Tachdjian et al., 2003; Selice et al., 2010). This has resulted in the birth of healthy children, following ICSI.

On the other hand, novel preventive measures have been proposed to preserve fertility in KS patients, although these are not yet applicable in the routine setting (Krausz and Chianese, 2014). Medical treatments for hypo-androgenism during the transition into adulthood were focused on fertility preservation and testosterone replacement therapy (TRT), and alleviation of current or future consequences of testicular fibrosis (Gies et al., 2014). Microdissection testicular sperm extraction is an effective sperm retrieval technique for men with KS. Men with hypogonadism who respond to medical therapy may have a better chance of sperm retrieval (Ramasamy et al., 2009). In such cases, the semen samples or testicular tissue samples (obtained by microsurgical testis sperm extraction) of boys with KS could be frozen at the onset of puberty (Gies et al., 2012). Bakircioglu et al. (2011) reported similar sperm recovery rates in men with KS and those with NOA and normal karyotypes. The fertilization rate was (statistically) significantly lower in men with KS than in men with non-obstructive azoospermia; however, the pregnancy and abortion rates were found to be similar. These therapeutic advances have provided azoospermic 47, XXY men with an opportunity for biological paternity (Oates, 2012).

Despite the success of sperm retrieval and ICSI, many areas of early aggressive hormonal 
spermatogenesis (and its natural history) and the appropriate management of these patients remains controversial (Mehta and Paduch, 2012; Sigman, 2012). Androgenotherapy is a common treatment for Klinefelter syndrome; however, it carries a risk of decreasing focal spermatogenesis by lowering the level of gonadotropins in the patients. Several arguments have suggested that this focal spermatogenesis decreases with age (Plotton et al., 2010). In addition, inadequately treated hypogonadism in Klinefelter syndrome patients increases the recognized psychosocial morbidity of patients. Therefore, there is a need for prospective planning and timely support for young men with KS, to ameliorate the current poor psychosocial outcomes (Simm and Zacharin, 2006). Ferhi et al. (2009) have reported that testicular sperm extraction or testicular sperm aspiration should be performed before the critical age of 32 years. Therefore, the optimal testosterone regimen for patients with KS remains to be determined (Bojesen and Gravholt, 2007).

The successful delivery of healthy children using sperms from men with KS has led to the involvement of reproductive endocrinologists and urologists in the care of patients with KS becoming commonplace. The new areas of research include the investigation of optimal methods of hormonal manipulations, preservation of fertility in adolescents, and development of universal early screening programs for KS (Paduch et al., 2009). Preventive care is to be provided from the time of diagnosis, preferentially using a multidisciplinary approach, including that from an endocrinologist, clinical psychologist or psychiatrist, neurologist, urologist, geneticist, sexologist, and a fertility team (Gies et al., 2014). This indicates the need to improve the genetic counseling process for KS patients.

In this study, the clinical characteristics of men with non-mosaic Klinefelter syndrome in northeastern China, and its implications in genetic counseling have been reported.

\section{MATERIAL AND METHODS}

\section{Patients}

One hundred and fifty nine patients with male infertility were diagnosed with non-mosaic Klinefelter's syndrome from January 2009 to December 2014 by chromosomal analysis, using G-banding techniques at the Andrology Laboratory of the Second Hospital of Jilin University. A physical examination was conducted to determine the age, height, weight, and testis volume of all patients.

\section{Semen analysis and semen cytology examination}

Semen analysis was performed according to the recommended World Health Organization guidelines (World Health Organization, 1999). If no sperm was found, semen cytology examination was conducted by sedimentation of semen samples through centrifugation, washing thrice with phosphatebuffered saline ( $\mathrm{pH}$ 7.2), spreading the washed semen on glass slides, and allowing the spread semen to air-dry. Hematoxylin-eosin staining was performed on the specimen after fixing with $95 \%$ alcohol (Jiang et al., 2014). The cells were examined under high magnification using a 40X light microscope.

\section{Cytogenetic analysis}

Peripheral blood $(0.5 \mathrm{~mL})$ was collected from all patients in sterile tubes containing $30 \mathrm{U} /$ $\mathrm{mL}$ heparin; the samples were subjected to G-banding, using cultured peripheral blood lymphocytes (Zhang et al., 2013). At least 20 metaphases were analyzed per patient. Chromosomal abnormalities were described according to the International System for Human Cytogenetic Nomenclature (2009). 


\section{Hormone analysis}

The plasma follicle stimulating hormone (FSH), luteinizing hormone (LH), and T levels were measured by radio-immunoassay (Sex Hormone Detection Kit; Jiuding BioMed Co. Ltd., Tianjin, China). The normal reference ranges for $\mathrm{FSH}, \mathrm{LH}$, and T were 0.5-15 mIU/mL, 0.4-6.8 mIU/ $\mathrm{mL}$, and 3.2-16.8 $\mathrm{ng} / \mathrm{mL}$, respectively.

\section{Statistical analysis}

All data was analyzed using SPSS v.17.0 for Windows (SPSS, Inc., Chicago, IL, USA). Parametric variables were compared by independent sample $t$-tests. All results are reported as means \pm standard deviation. $\mathrm{P}<0.05$ was considered to be statistically significant. Possible independent factors for semen volume were determined by Spearman correlation analysis.

\section{RESULTS}

Of the 3863 infertile men, 159 (4.12\%) with non-mosaic KS were included in this study. Of the 159 non-mosaic KS patients, sperm was observed in the ejaculate of 5 patients (3.14\%) after conventional semen analysis, and 9 cases (5.66\%) after centrifugation (2-9 sperms); these were included in this study. The germ cells were observed in the $12(7.55 \%)$ of non-mosaic KS patients after semen cytology examination. No sperm and germ cells were observed in 133 cases.

Figure 1 showed the age distribution of patients diagnosed with $\mathrm{KS}$. Less than $1 \%(0.63 \%)$ of the KS patients were $<20$ years, while a majority belonged to the $20-30$ year age group. Only one of the included cases was diagnosed at 18 years of age; the others cases were diagnosed when faced with the question of reproduction.

The clinical characteristics of KS patients with and without sperm or germ cells are as follows: the mean age of the patients with sperm or germ cells was lower than the mean age of patients without sperm or germ cells $(P<0.05)$. However, the patients with sperm or germ cells showed a higher semen volume than those without sperm or germ cells $(P<0.05 ;$ Table 1$)$. Comparison of the height, weight, testicular volume, and serum $\mathrm{FSH}, \mathrm{LH}$, and $\mathrm{T}$ of patients with and without sperm cells were not significantly different $(P>0.05)$ (Table 1).

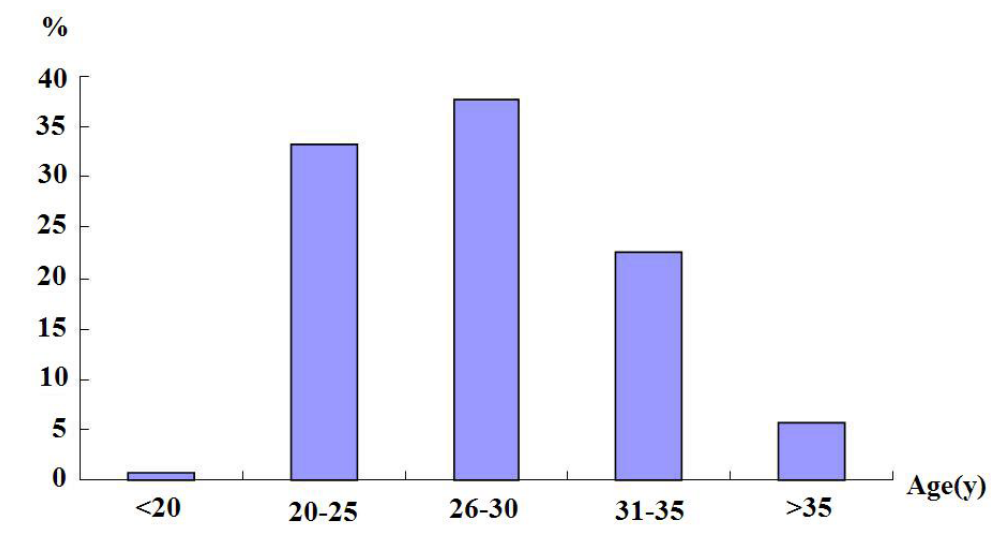

Figure 1. Age distribution of patients diagnosed with Klinefelter Syndrome. 
Table 1. Clinical parameters of 159 patients with non-mosaic Klinefelter syndrome (KS).

\begin{tabular}{lccc}
\hline Characteristic & KS male with sperm or germ cells $(\mathrm{N}=26)$ & KS male without sperm or germ cells $(\mathrm{N}=133)$ & P value \\
\hline Age $($ years $)$ & $26.27 \pm 3.34$ & $28.44 \pm 4.87$ & $0.032^{*}$ \\
Height $(\mathrm{cm})$ & $173.88 \pm 5.46$ & $175.04 \pm 4.98$ & 0.290 \\
Weight $(\mathrm{kg})$ & $77.54 \pm 15.00$ & $79.53 \pm 11.59$ & 0.448 \\
Testicular volume $(\mathrm{cc})$ & & & \\
Left & $4.19 \pm 2.99$ & $3.96 \pm 2.57$ & 0.685 \\
Right & $4.65 \pm 3.19$ & $4.13 \pm 2.69$ & 0.379 \\
Semen volume $(\mathrm{mL})$ & $3.61 \pm 1.04$ & $3.10 \pm 1.13$ & $0.035^{*}$ \\
FSH $(\mathrm{mlU} / \mathrm{mL})$ & $17.76 \pm 3.98$ & $18.85 \pm 5.91$ & 0.248 \\
LH $(\mathrm{mlU} / \mathrm{mL})$ & $10.34 \pm 5.49$ & $9.34 \pm 2.63$ & 0.155 \\
T $(\mathrm{ng} / \mathrm{mL})$ & $3.57 \pm 1.30$ & $3.14 \pm 1.32$ & 0.132 \\
\hline
\end{tabular}

$\mathrm{FSH}=$ follicle-stimulating hormone $(0.5-15 \mathrm{mIU} / \mathrm{mL}) ; \mathrm{LH}=$ luteinizing hormone $(0.4-6.8 \mathrm{mlU} / \mathrm{mL}) ; \mathrm{T}=$ testosterone $(3.2-$ $16.8 \mathrm{ng} / \mathrm{mL}$ ). ${ }^{*} \mathrm{P}<0.05$ compared to $\mathrm{KS}$ male with sperm or germ cells.

The Spearman correlation analysis revealed that the semen volume was negatively correlated with the age of KS patients $(r=-0.194, \mathrm{P}=0.014)$ and the ratio of serum $\mathrm{LH}$ and $\mathrm{T}(\mathrm{r}$ $=-0.164, \mathrm{P}=0.039)$. We observed no significant correlation between the serum $\mathrm{FSH}, \mathrm{LH}$, and $\mathrm{T}$ levels and the semen volume $(P>0.05)$.

\section{DISCUSSION}

Genetic abnormalities were identified in approximately $15 \%$ of the male infertility cases. KS, with the 47, XXY karyotype, is a result of aneuploidy of the sex chromosomes, and is one of the commonest types of congenital chromosomal disorder in infertile males. The prevalence of KS (ranging from $0.1 \%$ to $0.2 \%$ in newborn male infants) rises up to $3-4 \%$ among infertile males and $10-12 \%$ in azoospermic patients (Forti et al., 2010). Bak et al. (2012) reported a frequency of occurrence of Klinefelter syndrome of 179/1876 (9.54\%) in azoospermic males. On the other hand, we obtained an outcome of 159/3863 (4.12\%; non-mosaic KS) in infertile males.

Until recently, KS with a homogenous $47, \mathrm{XXY}$ karyotype was considered to be a model of absolute male sterility (Plotton et al., 2011). However, recent studies have indicated that men with KS are not always sterile. Some of these patients have shown the presence of sperm in the semen or testis. Selice et al. (2010) reported that 7 out of 84 patients $(7 / 84 ; 8.3 \%)$ had sperm in the ejaculate. In a few cases, men with non-mosaic KS have ejaculated spermatozoa that can result in the birth of a healthy child following ICSI. In this study, 5 cases $(3.14 \%)$ with non-mosaic KS showed the presence of sperm in the ejaculate, while 9 cases $(5.66 \%)$ exhibited symptoms of cryptozoospermia.

This could be attributed to local spermatogenesis in the testis of KS patients. Adult KS patients can be divided into three subgroups: those showing focal spermatogenesis, those with spermatogonia, and patients from whom no germ cells can be recovered (van Saen et al., 2012a). This type of focal spermatogenesis could be decrease with age (Plotton et al., 2014).

However, many KS patients could be diagnosed before puberty. Rock et al. (2014) reported that only 4 infertile males with KS $(2.7 \%)$ were already aware of their diagnosis. Forti et al. (2010) reported that only $10 \%$ of Klinefelter patients were diagnosed prior to puberty. So far, only approximately $25 \%$ of all KS patients have received an accurate diagnosis during their lifetimes (Bojesen and Gravholt, 2007; Nieschlag, 2013). In this study, only 1 patient with KS was diagnosed at 18 years of age; the other cases were diagnosed because of concerns regarding their reproductive capacities (Figure 1). 
Early diagnosis and treatment improves the quality of life and the overall health of men with Klinefelter syndrome (Paduch et al., 2008). However, there remain some controversies regarding the age of testosterone replacement therapy. Early detection of this syndrome is recommended to facilitate proper treatment and intervention at the appropriate age and stage of disease development (Aksglaede et al., 2013). Bojesen and Gravholt (2007) reported that patients with KS should be treated with lifelong testosterone supplementation starting from puberty, to secure the proper masculine development of sexual characteristics, and to prevent long-term deleterious consequences of hypogonadism. Fertility preservation might be proposed for adolescent KS patients immediately after the onset of puberty, when it is possible to collect a semen sample (Rives et al., 2013). Testicular tissue cryopreservation in KS adolescents should be recommended as soon as possible, probably before the detection of hormonal changes of failing Sertoli cell function (Van Saen et al., 2012b). However, lower retrieval rates have been reported in a small subset of KS adults, who previously received exogenous testosterone (Mehta and Paduch, 2012). Inadequately treated hypogonadism in KS is known to increase recognized psychosocial morbidity. Previous studies have demonstrated the need for prospective planning and timely support for young men with KS, in order to ameliorate the current poor psychosocial outcomes (Simm and Zacharin, 2006).

A majority of the KS patients $(81.9 \%)$ displayed normal secondary sexual characteristics (Rock et al., 2014). Testosterone has the strongest negative association with the severity of signs and symptoms in patients with Klinefelter syndrome. It influences the reproductive capacity, as well as the manifested signs and symptoms of hypogonadism. Furthermore, it is also associated with the various aspects of life in these patients (Bak et al., 2012). In addition, age has been found to be an important factor for testicular sperm recovery and successful sperm retrieval in patients with non-mosaic KS (Okada et al., 2005; Emre Bakircioglu et al., 2006; Ferhi et al., 2009). Therefore, we studied the clinical characteristics of KS patients with and without sperm or germ cells. Table 1 summarizes the significant differences between the mean age and semen volume in patients with and without sperm or germ cells. On the other hand, a comparison of the height, weight, testicular volume, and serum $\mathrm{FSH}, \mathrm{LH}$, and T levels in patients with and without sperm were not statistically different.

Further studies demonstrated the negative correlation of semen volume with the age of KS patients $(P<0.05)$ and the ratio of serum LH and T $(\mathrm{LH} / \mathrm{T})(P<0.05)$. Aksglaede et al. (2009) reported that semen volume, adjusted for the duration of abstinence, was significantly lower in KS patients compared to members of the control group. The lower semen volume supports the theory of $47, \mathrm{XXY}$ patients being androgen insufficient. Semen volume is strongly dependent on $\mathrm{T}$, which stimulates seminal fluid production in the epididymis and seminal vesicles.

Therefore, genetic counseling for KS patients should attempt or consider early diagnosis and timely treatment. KS patients desiring to be fertile must undergo medical treatment (during the transition into adulthood), focused on the preservation of fertility and testosterone replacement therapy; however, a multidisciplinary approach should be preferentially considered. KS patients who do not wish to reproduce must consider improving their quality of life.

In summary, the prevalence of non-mosaic KS was found to be $4.12 \%$ in the northeast infertile male population. The rate of early diagnosis was lower in KS patients, with a majority of the diagnosis resulting from the patients' wish to reproduce. The mean age of patients producing sperm or germ cells was significantly lower; the semen volume of these patients, on the other hand, was significantly higher. However, the semen volume was negatively correlated with the age and ratio of $\mathrm{LH} / \mathrm{T}$ in $\mathrm{KS}$ patients.

The genetic counseling for KS patients should focus on early diagnosis and timely treatment. The use of testosterone replacement therapy and/or micro-dissection testicular sperm 
extraction methods, or a multidisciplinary approach should be preferentially considered for the preservation of fertility. In addition, all KS patients should consider improving their quality of life.

\section{Conflicts of interest}

The authors declare no conflict of interest.

\section{ACKNOWLEDGMENTS}

The excellent technical assistance provided by the staff of the Genetics Laboratory is greatly appreciated.

\section{REFERENCES}

Aksglaede L, Jørgensen N, Skakkebaek NE and Juul A (2009). Low semen volume in 47 adolescents and adults with 47,XXY Klinefelter or 46,XX male syndrome. Int. J. Androl. 32: 376-384.

Aksglaede L, Link K, Giwercman A, Jørgensen N, et al. (2013). 47,XXY Klinefelter syndrome: clinical characteristics and agespecific recommendations for medical management. Am. J. Med. Genet. C Semin. Med. Genet. 163C: 55-63.

Bak CW, Byun JS, Lee JH, Park JH, et al. (2012). Clinical and social characteristics of Korean men with Klinefelter syndrome. Int. J. Urol. 19: 443-449.

Bakircioglu ME, Ulug U, Erden HF, Tosun S, et al. (2011). Klinefelter syndrome: does it confer a bad prognosis in treatment of nonobstructive azoospermia? Fertil. Steril. 95: 1696-1699.

Bar G, Lunenfeld E and Levitas E (2014). Klinefelter syndrome: genetic aspects, characteristics and reproduction - present and future. Harefuah 153: 342-366.

Bojesen A and Gravholt CH (2007). Klinefelter syndrome in clinical practice. Nat. Clin. Pract. Urol. 4: $192-204$.

Crüger D, Toft B, Agerholm I, Fedder J, et al. (2001). Birth of a healthy girl after ICSI with ejaculated spermatozoa from a man with non-mosaic Klinefelter's syndrome. Hum. Reprod. 16: 1909-1911.

Emre Bakircioglu M, Erden HF, Kaplancan T, Ciray N, et al. (2006). Aging may adversely affect testicular sperm recovery in patients with Klinefelter syndrome. Urology 68: 1082-1086.

Ferhi K, Avakian R, Griveau JF and Guille F (2009). Age as only predictive factor for successful sperm recovery in patients with Klinefelter's syndrome. Andrologia 41: 84-87.

Forti G, Corona G, Vignozzi L, Krausz C, et al. (2010). Klinefelter's syndrome: a clinical and therapeutical update. Sex Dev. 4: 249-258.

Gies I, De Schepper J, Goossens E, Van Saen D, et al. (2012). Spermatogonial stem cell preservation in boys with Klinefelter syndrome: to bank or not to bank, that's the question. Fertil. Steril. 98: 284-289.

Gies I, Unuane D, Velkeniers B and De Schepper J (2014). Management of Klinefelter syndrome during transition. Eur. J. Endocrinol. 171: R67-R77.

Jiang YT, Dong Y, Yu XW, Du RC, et al. (2014). Sperm retrieval from patients with nonmosaic Klinefelter's syndrome by semen cytology examination. Genet. Mol. Res. 13: 1848-1854.

Krausz C and Chianese C (2014). Genetic testing and counselling for male infertility. Curr. Opin. Endocrinol. Diabetes Obes. 21: 244-250.

Mehta A and Paduch DA (2012). Klinefelter syndrome: an argument for early aggressive hormonal and fertility management. Fertil. Steril. 98: 274-283.

Nieschlag E (2013). Klinefelter syndrome: the commonest form of hypogonadism, but often overlooked or untreated. Dtsch. Arztebl. Int. 110: 347-353.

Oates RD (2012). The natural history of endocrine function and spermatogenesis in Klinefelter syndrome: what the data show. Fertil. Steril. 98: 266-273.

Okada H, Goda K, Yamamoto Y, Sofikitis N, et al. (2005). Age as a limiting factor for successful sperm retrieval in patients with nonmosaic Klinefelter's syndrome. Fertil. Steril. 84: 1662-1664.

Paduch DA, Fine RG, Bolyakov A and Kiper J (2008). New concepts in Klinefelter syndrome. Curr. Opin. Urol. 18: $621-627$.

Paduch DA, Bolyakov A, Cohen P and Travis A (2009). Reproduction in men with Klinefelter syndrome: the past, the present, and the future. Semin. Reprod. Med. 27: 137-148. 
Plotton I, Brosse A and Lejeune H (2010). Is it useful to modify the care of Klinefelter's syndrome to improve the chances of paternity? Ann. Endocrinol. 71: 494-504.

Plotton I, Brosse A, Groupe Fertipreserve and Lejeune H (2011). Infertility treatment in Klinefelter syndrome. Gynecol. Obstet. Fertil. 39: 529-532.

Plotton I, Brosse A, Cuzin B and Lejeune H (2014). Klinefelter syndrome and TESE-ICSI. Ann. Endocrinol. (Paris) 75: $118-125$.

Ramasamy R, Ricci JA, Palermo GD, Gosden LV, et al. (2009). Successful fertility treatment for Klinefelter's syndrome. J. Urol. 182: $1108-1113$.

Rives N, Milazzo JP, Perdrix A, Castanet M, et al. (2013). The feasibility of fertility preservation in adolescents with Klinefelter syndrome. Hum. Reprod. 28: 1468-1479.

Rock A, Marcelli F, Robin G, Mitchell V, et al. (2014). Clinical and paraclinical features of Klinefelter syndrome consulting for male infertility. Prog. Urol. 24: 757-763.

Selice R, Di Mambro A, Garolla A, Ficarra V, et al. (2010). Spermatogenesis in Klinefelter syndrome. J. Endocrinol. Invest. 33: 789-793.

Sigman M (2012). Klinefelter syndrome: how, what, and why? Fertil. Steril. 98: 251-252.

Simm PJ and Zacharin MR (2006). The psychosocial impact of Klinefelter syndrome - a 10 year review. J. Pediatr. Endocrinol. Metab. 19: 499-505.

Tachdjian G, Frydman N, Morichon-Delvallez N, Dû AL, et al. (2003). Reproductive genetic counselling in non-mosaic 47,XXY patients: implications for preimplantation or prenatal diagnosis: Case report and review. Hum. Reprod. 18: $271-275$.

Van Saen D, Tournaye H and Goossens E (2012a). Presence of spermatogonia in 47,XXY men with no spermatozoa recovered after testicular sperm extraction. Fertil. Steril. 97: 319-323.

Van Saen D, Gies I, De Schepper J, Tournaye H, et al. (2012b). Can pubertal boys with Klinefelter syndrome benefit from spermatogonial stem cell banking? Hum. Reprod. 27: 323-330.

World Health Organization (1999). WHO Laboratory Manual for the examination of human semen and sperm-cervical mucus interaction. 4th ed. University Press, Cambridge.

Zhang HG, Zhang ZB, Wang RX, Yu Y, et al. (2013). Male infertility in Northeast China: molecular detection of Y chromosome microdeletions in azoospermic patients with Klinefelter's syndrome. Genet. Mol. Res. 12: 4972-4980. 